\title{
IDENTIFIKASI GAYA BELAJAR (VISUAL, AUDITORIAL DAN KINESTETIK) MAHASISWA TADRIS BAHASA INGGRIS KELAS 3F IAIN SYEKH NURJATI CIREBON

\author{
Identification Of Learning Styles (Visual, Auditorial And Kinesthetic) English Tadris \\ Students Class 3F IAIN Syekh Nurjati Cirebon
}

\author{
Oleh: Lina Rahmawati* dan Septi Gumiandari*** \\ e-mail: linarahmawati9992@gmail.com
}

\begin{abstract}
ABSTRAK
Gaya belajar pada mahasiswa dinilai sangat penting untuk proses pembelajaran dan hasil belajar, disamping itu juga juga dosen memiliki peran penting dalam menerapkan proses belajar pada mahasiswa yang telah disesuaikan dengan gaya belajar mahasiswa. Dari penelitian yang telah dilakukan bertujuan untuk mengidentifikasi dan menganalisis gaya belajar dan hasilnya pada mahasiswa program studi bahasa inggris kelas F IAIN Syekh Nurjati Cirebon. Pada penelitian kali ini disebut dengan penelitian deskriptif. Penelitian ini dilakukan dengan cara memberikan angket/kuesioner kepada mahasiswa prodi bahasa inggris kelas $\mathrm{F}$, yang mana kuesioner tersebut berisikan beberapa pernyataan yang telah disesuaikan dengan teori gaya belajar, yaitu visual, kinestetik dan auditorial. Pada penelitian ini terdapat 28 mahasiswa yang mengisi kuesioner dan didapatkan hasil bahwa dari 28 mahasiswa tersebut, 16 diantaranya memiliki gaya gaya belajar visual, 3 diantaranya mempunyai gaya belajar auditorial, dan 19 mahasiswa mempunyai gaya belajar kinestetik, selain itu juga ada beberapa mahasiswa memiliki lebih dari satu gaya belajar/gaya belajar campuran. Dapat dilihat bahwa gaya belajar visual mendominasi disbanding gaya belajar yang lainnya. Karena pada dasarnya, mahasiswa memiliki karakteristik cara dalam menerima informasi lebih dari satu, namun tetap hanya satu cara saja yang akan lebih menonjol pada setiap mahasiswa. Berdasarkan hasil tersebut menyatakan bahwa cara belajar yang dimiliki setiap mahasiswa atau setiap individu tentunya akan sangat berbeda beda.
\end{abstract}

Kata Kunci : Gaya belajar, Visual, Auditorial dan Kinestetik.

\section{ABSTRACT}

The learning style of students is considered very important for the learning process and learning outcomes, besides that lecturers also have an important role in implementing the learning process for students who have been adapted to student learning styles. From the research that has been carried out, it aims to identify and analyze the learning styles and results of the students of the $F$ class English study program at IAIN Sheikh Nurjati Cirebon. In this research, it is called descriptive research. This research was conducted by giving a questionnaire/questionnaire to students of class $F$ English study program, in which the questionnaire contains several statements that have been adapted to the theory of learning styles, namely visual, kinesthetic and auditory. In this study, there were 28 students who filled out the questionnaire and the results showed that of the 28 students, 16 of them had a visual learning style, 3 of them had an auditory learning style, and 19 students had a kinesthetic learning style. one learning style/mixed learning style. It can be seen that visual learning styles dominate compared to other learning styles. Because basically, students have the characteristics of more than one way of receiving information, but there is only one way that will stand out more for each student. Based on these results, it is stated that the way of learning that is owned by each student or each individual will certainly be very different.

Keyword : Learning styles, Visual, Auditorial and Kinesthetic.

Lina Rahmawati* dan Septi Gumiandari** 


\section{PENDAHULUAN}

Faktor terpenting dalam suatu kehidupan manusia salah satunya yaitu pendidikan, sedangkan keberhasilan pendidikan secara formal khusunya disekolah dapat dilihat dari gaya belajarnya atau Learning style (LS). Menurut Rambe (2019), gaya belajar yaitu suatu metode yang mudah bagi mahasiswa untuk menerima informasi kemudian mengaturnya dan mengelola informasi tersebut yang diterima. Salah satu sarana pendidikan yaitu universitas, yang mana mahasiswa yang menjadi salah satu bagian yang paling utama yang menunjang sistem pendidikan di universitas. Pada tingkat universitas tentunya proses pembelajaran jauh berbeda dengan pendidkan diSMP/SMA. Di tingkat universitas mahasiswa dituntut menjadi mahasiswa yang mandiri tidak lagi dituntun oleh pengajar melainkan mahasiswa diharuskan dapat mencari dan menganalisis suatu permasalahan yang ada disekitarnya, dan diharapkan mampu untuk memperluas materi yang diberikan dosen secara mandiri. Disamping itu juga seorang mahasiswa ratarata memiliki kecerdasan kognitif yang telah matang, salah satunya yaitu daalam memikirkan sesuatu dan tentunya sudah dapat berfikir secara rasional. Karakter merupakan cara setiap individu dalam berfikir dan berprilaku dan menjadi suatu kebiasaan pada kehidpan baik secara mikro maupun makro. Dengan hal tersebut dapat dilihat bahwa cara berfikir mahasiswa tentunya akan sangat berbeda dengan cara berfikir anak- anak usia 10 tahun. Mahasiswa akan meiliki pemikiran yang lebih matang dan kritis dalam setiap pemikirannya.

Dalam mempelajari sesuatu mahasiswa juga tentunya akan sangat berbeda dengan bagaimana anak umur 10 tahun. Saat menerima informasi mahasiswa tentunya akan lebih bijak dan menyaringnya terlebih dahulu sebelum iya terima informasi tersebut.
Sedangkan hasil dari proses belajar mahasiswa tentunya disebabkan oleh berbagai macam sebab selain dari lingkungan tapi melainkan karena bagaimana ia menerima informasi dan kemudian mengolahnya. Hasil belajar pada mahasiswa salahsatunya dapat disebabkan oleh gaya belajarnya. Apakah dalam proses pembelajaran mahasiswa menggunakan gaya belajar yang ia sukai atau tidak.

Dan dalam mempelajari sesuatu, mahasiswa juga memiliki keberagaman dalam hal gaya belajar, sedangkan gaya belajar sangat berpengaruh terutama dalam proses kegiatan belajar mengajar, terutama untuk meningkatkan keberhasilan pada proses pentransferan ilmu. Learning style yaitu sebuah kecenderungan dari setiap individu dalam mempelajari suatu ilmu dengan caranya senidri, proses tersebut dapat berupa pergerakan diri, penyerapan pada materi, atau suatu cara mahasiswa dalam menerima, dan mengolah suatu informasi dengan caranya sendiri yang sesuai menurut dirinya, (Joko,2006). Sedangkan menurut Saija (2020), menyatakan bahwa gaya belajar setiap individu berhubungan erat dengan perilaku kognitif, afektif dan psikologikalyang beragam pada setiap individu dalam memahami dan mengatur dirisnya sendiri dalam memecahkan suatu permasalahan. untuk membuat proses belajar mengajar menjadi efektif dan lebih efesian maka oleh karena itu penting untuk mengenal gaya belajar pada individu, (Magdalena:2020). Oleh karena itu pada tingkat universitas, dosen diharapkan mampu untuk mengetahui proses pentransferan informasi seperti apa yang cenderung lebih disukai oleh mahasiswa ditingkat universistas, (Wahyuni,2017). Sedangkan pendapat dari DePorter (2000) "Gaya belajar setiap individu merupakan cara dimana individu tersebut dapat menerima informasi kemudian menyerapnya lalu 
mengolahnya dengan baik." selain itu juga proses pembelajaran akan dirasa lebih efesien dangan menerapkan system pembelajaran yang disesuaikan gaya belajar mahasiswa.

Secara umum gaya belajar memiliki tiga jenis, yang pertama yaitu visual, auditorial dan kinestetik. Biasanya setiap individu terdapat kecenderungan dalam mempelajari sesuatu dengan cara yang beragama atau yang biasa disebut gaya belajar campuran, menurut peneliti dapat dikatakan bahwa setiap mahasiswa tidak hanya memiliki satu saja gaya belajar, melainkan dapat memiliki gaya belajar yang beragam atau gaya belajar campuran, namun macam macam gaya belajar tersebut salah satunya akan lebih mendominasi pada setiap mahasiswa.

Gaya belajar visual yaitu suatu proses penerimaan informasi yang berkaitan dengan indra penglihatan(mata). Karena bagi seseorang yang bergaya belajar visual mereka akan lebih paham saat belajar apabila yang mereka dapat melihatnya secara langsung, atau akan lebih mengingat pembelajaran apabila melihat gambar- gambar yang menarik, atau dengan warna - warna yang mencolok.

Gaya belajar auditorial merupakan proses penerimaan informasi yang erat kaitannya dengan indra pendengaran, mahasiswa yang memiliki gaya belajar ini akan mudah mengapal informasi apabila ia mendengarkan informasi tersebut. Selain itu juga orang yang memiliki gaya belaejar auditorial akan cenderung menjadi seseorang yang lebih tertarik dalam pembicaraan, salahsatunya yaitu bisa dalam bentuk diskusi dengan orang lain. (Wahyuni,2016:130).

Gaya belajar kinestetik adalah suatu cara proses menerima informasi yang erat kaitannya mengenai organ tubuh contohnya tangan dan kaki, gaya belajar ini akan lebih dalam proses penerimaan informasi melalui pergerakan, sentuhan dan suatu perbuatan.
Dari hal- hal tersebut pemilik gaya belajar kinestetik akan bisa mengingat suatu informasi dengan hal tersebut, (Magdalena dan Afiffah, 2020:4). Seorang yang memiliki gaya belajar kinestetik akan mengutamakan indera perasa dan gerakan-gerakan tubuh untuk mengingat informasi.

Pada penelitian kali ini peneliti mengangkat masalah mengenai gaya belajar, khususnya dalam mengidentifikasi gaya belajar mahasiswa. Namun sebelum ini peneliti juga telah membaca dan menelaah beberapa jurnal terkait gaya belajar pada siswa. Diantaranya penelitian yang dilakukan oleh Papilaya dan Huliselan (2016) yang berjudul " Identifikasi Gaya Belajar Mahasiswa" yang bertujuan : untuk mengidentifikasi gaya belajar mahasiswa. Sedangkan penelitian ini dilakukan dengan cara mensurvey dengan pendekatan kuantitatif dan menggunakan variable tunggal. Dan pada penelitian ini peneliti mengumpulkan data dengan teknik analisis statistic deskriptif. Secara keseluhan penelitian menghasilkan bahwa gaya belajar visual yang menjadi gaya belajar yang paling banyak dimiliki oleh mahasiswa FKIP Unpatti.

Penelitian yang dilakukan oleh Wahyuni (2017) memiliki tujuan untuk mengidentifikasi gaya belajar (visual, auditorial, kinestetik), yang mana pada penelitian ini penulis menganalisis bahwa suatu proses belajar pada mahasiswa Program Studi Pendidikan Matematika Universitas Bung Hatta, dinilai sangat begitu penting. Karena suatu penerimaan informasi dari dosen kepada mahasiswa tentunya akan sangat diperhatikan karena sangat berpengaruh pda bagaimana hasil belajar dari mahasiswa. Pada penelitian kali ini dinamakan dengan penelitian deskriptif, dengan mengidentifikasi seluruh mahasiswa Program Studi Pendidikan Matematika 
angkatan 2012-2015, dengan cara teknik Purposive sampling yaitu denganmembagikan kuesioner berupa angket. Dari hasil penelitian menjukan bahwa mahasiswa program studi pendidikan matematika memiliki kecenderungan gaya belajar yang bervariasi pada setiap angkatan disetiap tahunnya.

Dan penelitian yang dilakukan oleh Magdalena dan Afifah (2020) yang bertujuan : untuk mengidentifikasi gaya belajar siswa SDN CIKOKOL 2. Penelitian ini termasuk dalam penelitian deskriptif. Populasi yang diambil dalam penelitian ini adalah siswa kelas 3, 4, 5, dan 6 SDN CIKOKOL 2. Instrumen yang digunakan dalam penelitian ini berupa wawancara. Hasil analisis menunjukkan bahwa siswa SDN CIKOKOL 2 memiliki gaya belajar yang bervariasi yaitu Visual, Auditorial, dan Kinestetik. Dan setiap kelas tentunya memiliki satu gaya belajar yang paling menonjol.

Dari ketiga penelitian diatas menunjukan bahwa dengan mengidentifikasi gaya belajar pada siswa dan mahasiswa sangat penting untuk menunjang hasil belajar pada siswa dan akan membuat kegiatan belajar menjadi lebih efesien. Dari keberagaman karakter setiap individu dan juga keberagaman gaya belajar, dengan penelitian ini penulis ingin mengidentifikasi gaya belajar dari mahasiswa.

\section{METODE PENELITIAN}

Pada penelitian kali ini berjenis penelitian deskriptif. Penelitian ini dilakukan dengan cara memberikan angket/kuesioner kepada mahasiswa prodi bahasa inggris kelas $\mathrm{F}$, yang mana kuesioner tersebut berisikan beberapa pernyataan yang telah disesuaikan dengan teori gaya belajar, yaitu visual, kinestetik dan auditorial. Dengan hal tersebut dapat mengidentifikasi gaya belajar yang dimiliki oleh setiap mahasiswa.

Mengutip dari Wahyuni (2017:130),
Ghufron (2012) menyatakan bahwa dengan hal yang kurang tepat dilakukan saat proses pembelajaran yaitu mengajarkan bahan ajaran yang sama dan dengan cara yang sama pula pada setiap mahasiswa, namun hal tersebut dianggap kurang tepat karena dinilai tidak seuai seperti gaya belajar yang dimiliki pada masing- masing mahasiswa. Oleh karena itu, disinilah peran penting seorang dosen dalam penyampaian informasi atau bahan ajaran kepada mahasiswa yang disesuaikan dengan gaya belajar mahasiswa.

\section{HASIL PENELITIAN DAN PEMBAHASAN}

Menurut Waluyo (2014), hal yang pertama kali harus dihilngkan saat memulai belajar yaitu rasa takut yang muncul pada diri kita, saat otak kita merasa takut maka jaringan otak kita bisa dalam keadaan mapaan dengan ketidaktahuan atau bisa juga disebut dalam "status quo". Oleh karena itu rasa takut bisa sangat mempengruhi kita dalam proses belajar. Agar otak kita bisa memiliki banyak koneksi - koneksi sel neuron di otak kita maka kita harus melatihnya dengan cara menganalisis dan mengamati suatu permasalahan disekitar, selain itu juga banyak belajar dan membaca dapat memepengaruhi sel- sel neuron yang ada diotak kita. Dengan lebih banyak mengasah kemampuan berfikir, dan banyak menambah ilmu dengan belajar tentunya akan dapat membuat otak akan lebih cerdas dibandingan sebelumnya.

$$
\text { Dalam memudahkan proses }
$$
pembelajaran secara maksimal maka harus disesuaikan dengan bagaimana dari cara atau proses belajar yang disukai oleh masingmasing mahasiswa. Oleh karena itu, proses pembekalan ilmu dari dosen ke mahasiswa bisa berjalan secara maksimal. Dimana saat proses pemebelajaran mahasiswa yang menggunakan gaya belajar yang dimilikinya maka akan memudahkan mahasiswa dalam 
menyerap suatu informasi atau materi yang diberikan dosen. Hal lain juga dikarenakan kepribadian, abilitas (kecakapan), emosional, dan minat yang ada pada masing- masing mahasiswa memiliki perbedaan. Sedangkan hal- hal tersebut sangat perlu diperhatikan untuk menunjang proses penyerapan informasi saat proses pembelajaran, (Anggrawan, 2019). Cara untuk mempelajari sesuatu tentunya sangat akan berpengaruh dengan bagaimana karakteristik dari diri tersebut. Karakteristik atau sifatyang biasanya dimiliki oleh mahasiswa yang memiliki gaya belajar visual biasanya memiliki sifat perfeksionis, mereka akan cepat dalam berbicara, suka membaca, dan teliti atau detail dalam hal apapun. Sedangkan karakteristik yang dimiliki oleh pemilik gaya belajar auditorial yaitu mereka senang berbicara pada dirinya sendiri saat melakukan suatu hal, senang bercerita dibandingkan menulis cerita, dan aktif dalam berdiskusi. Sedangkan karakteristik yang dimiliki oleh model gaya belajar yang terakhir yaitu gaya belajar kinestetik yaitu lebih aktif dalam bergerak, suka melakukan banyak hal, tidak betah saat harus belajar dalam keadaan duduk dengan waktu yang lama, dan kemungkinan tulisan pemilik gaya belajar kinestetik itu jelek.

Berikut ini merupakan data dari mengidentifikasi gaya belajar mahasiswa yang disajikan dalam bentuk grafik :

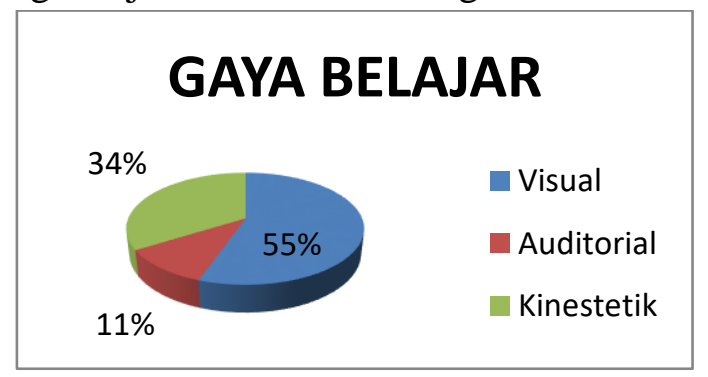

Dari diagram diatas menunjukan bahwa mahasiswa kelas $3 \mathrm{~F}$ cenderung memiliki gaya belajar visual, yang mana lebih mengoptimalkan indra penglihatan. Setengah dari kelas 3F memiliki gaya belajar visual.
Setiap individu tentunya dapat belajar, namun saat belajar juga tentunya kita memiliki gaya atau cara belajar yang berbedabeda agar suatu informasi tersebut dapat sampai dan bisa dipahami, itulah alasan yang dinilai sangat utama untuk kita mengetahui gaya belajar pada mahasiswa. Dengan karaketiristik yang dimiliki setiap individu itu beragam, maka tidak ada satu pendekatan yang bisa dierima olehsetiap individu, dan jika cara dalam memberikan suatu informasi atau bahasan ajaran kepada mahasiswa itu dirancang atau disusun berdasarkan gaya belajar makan dinilai akan sangat berpengaruh dalam proses pembelajaran, mahasiswa akan lebih bisa konsentrasi dan fokus pada proses pembelajaran dan bisa memahami materi yang dinilai memiliki nilai kesulitan yang tinggi. Bahkan setiap individu memiliki gaya belajar yang beragam/ kombinasi, itu bisa disebakan karena situasinya yang sedang dihadapi, atau tergantung dengan keadaan saat belajar, (Wahyuni,2017:131). Dengan ini, dosen juga tentunya memiliki peran yang sangat utama untuk mahasiswa dalam menyampaikan informasi atau bahan ajaran dikelas. Dosen diharapkan mampu memahami karakteristik setiap mahasiswa untuk menerapkan cara pembelajaran didalam kelas.

Apabila pengajar/ dosen ingin materi atau bahan ajaran apa yang disampaikan benar-benar bisa diterima dan juga dapat dimengerti oleh mahasiswa, maka sebaiknya dosen atau pengajar bisa menggabungkan berbagai pendekatan atau cara pengajaran Dengan hal tersebut memungkinkan mahasiswa akan lebih nyaman untuk bisa mengolah informasi dengan baik, selain itu juga diharapkan mahasiswa dapat menyerap dan menganalisis informasi yang disampaikan dosen dengan baik, dan kemudian dapat mencerna informasi tersebut dengan baik pula. (Wahyuni,2017:132). Tentunya pada 
setiap kelas memiliki gaya belajar yang beragam pada setiap mahasiswanya, maka dosen akan bingung dalam menerapkan gaya belajar apa yang tepat dilakukan didalam kelas. Disini dapat disarankan untuk dosen menerapkan proses belajar yang beragam setiap kali menyampaikan informasi, agar setiap mahasiswa dengan beragam gaya belajarnya akan merasa puas dan adil, dan mahasiswapun tentunya bisa menerima informasi dari dosen dan mengolahnya dengan baik, karena sesuai dengan gaya belajar setaip mahasiswa tersebut.

Oleh karena itu, pegajar atau dosen diharapkan mampu untuk mengetahui cara belajar seperti apa yang diinginkan oleh mahasiswanya, karena dengan mengetahui gaya belajar tentunya dosen akan paham dan memiliki strategi yang dinilai tepat atau mempu untuk proses belajar yang disukai oleh setiap mahasiswanya didalam kelas. Dan dengan pengajar menerapkan proses belajar yang menyesuaikan berdasarkan keinginan dari mahasiswanya, tentu mahasiswa akan menjadi nyaman dan bisa menyerap informasi yang diberikan dosen secara maksimal. Dari sini dapat dilihat bahwa dengan mengetahu gaya belajar mahasiswa didapatkan sebuahproses pembelajaran yang baik untuk dosen maupun mahasiswanya.

\section{KESIMPULAN}

Dosen disetiap perguruan tinggi atau universitas tentunya memiiki model pembelajaran yang dipilih sendiri berdasarkan alasan dan pertimbangan sendiri untuk diselenggarakan pada pembelajaran mahasiswa. Hasil belajar mahasiswa tentunya disebabkan oleh beberapa faktor, dan disini faktor yang paling utama yaitu penerapan proses belajarnya, faktor gaya atau cara belajarlah yang merupakan faktor terpenting untuk dapat menghasilkan proses belajar dan hasil belajar yang dinilai akan berdampak baik. Karena cara atau gaya belajar setiap individu dapat menjadikan individu itu dapat belajar dengan nyaman dan enjoy. (Anggrawan:2019). Dengan memperhatikan cara belajar yang dimiliki oleh setiap mahasiswa tentunya diharapkan dapat menghasilkan proses belajar dengan baik secar maksimal. Dan dapat disimpulkan bahwa sebagai pengajar sendiri diharapkan bisa menerapkan system belajar yang telah disusun sedemikian rupa dan tentunya telah disesuaikan dengan baik berdasarkan cara belajar yangan diinginkan oleh mahasiswanya. Dengan hal tersebut mahasiswa dirasa akan lebih nyaman dan mungkin akan lebih memudahkan dalam menerima informasi yang kemudian menyerap dan mengolahnya dengan baik.

Berdasarkan dari hasil penelitian dan pembahasan mengahsilkan bahwa mahasiswa IAIN Syekh Nurjati Cirebon program studi Tadris bahasa Inggris semester 3 kelas $\mathrm{F}$ memiliki gaya belajar yang beragam. Namun gaya belajar yang mendominasi kelas $\mathrm{F}$ yaitu gaya belajar visual, yang merupakan gaya belajar dengan mengoptimalkan indra penglihatan. 55\% dari 28 siswa memiliki gaya belajar visual, $11 \%$ memiliki gaya belajar Auditorial dan 34\% memiliki gaya belajar kinestetik. Terlihat jelas bahwa gaya belajar yang mendominasi mahasiswa kelas $\mathrm{F}$ tersebut yaitu gaya belajar visual.

\section{DAFTAR PUSTAKA}

Anggrawan,A. (2019). Analisis Deskriptif Hasil Belajar Pembelajaran Tatap Muka Dan Pembelajaran Daring Menurut Gaya Belajar Mahasiswa. Jurnal MATRIK, 18(2), 339-346

Bire,A.L. Geradus,U.Bire,J. (2014). Pengaruh Gaya Belajar Visual, Auditorial, Dan Kinestetik Terhadap Prestasi Belajar Siswa. Jurnal Kependidikan 44,(2), 
168-174.

Damayanti,A.K. Pratitis,N.T. (2012). Gaya

Belajar Ditinjau dari Tipe Kepribadian dan Jenis Kelamin. Jurnal Psikologi Indonesia, 1( 2), 88-98

DePorter, Bobby \& Hernacki, Mike. (2000). Quantum Learning : Membiasakan Belajar Nyaman dan Menyenangkan, Bandung: Kaifa

Kusnida,F. Mulyani,M. Su'udi,A. (2015).Keefektifan Penggunaan Media Audio Visual Dan Media Komik Strip Dalam Pembelajaran Menulis Cerpen Yang Bermuatan Nilai-Nilai Karakter Berdasarkan Gaya Belajar. Jurnal Pendidikan Bahasa dan Sastra Indonesia 4, (2)

M. Joko Susilo. (2006). Gaya Belajar Menjadikan Makin Pintar, Yogyakarta : Pinus.

Magdalena.i. Affifah.A,N. (2020). Identifikasi Gaya Belajar Siswa (Visual, Auditorial, Kinestetik). Jurnal Pendidikan Dan Ilmu Sosial,2(1),1-8

Mulyani,L.S. Solihah,S. (2019). Analisis Tentang Gaya Belajar Siswa Berdasarkan Visual, Auditori, Kinestetik Pada Mata Pelajaran Biologi Man 1 Garut. Biology Education, 2(1)

Papilaya,J.O. Huliselan,N. (2016). Identifikasi Gaya Belajar Mahasiswa. Jurnal Psikologi Undip, 15(1), 56-63.

Papilaya,J.O. Huliselan,N.(2016). Identifikasi Gaya Belajar Mahasiswa. Jurnal Psikologi Undip, 15(1),65-63

Putra, Chandra Anugrah dan M Andi Setiawan. 2019. Penerapan Model Pembelajaran Circuit Learning Berbantuan Media Power Point Terhadap Hasil Belajar IPS. Jurnal Bidang Pendidikan Dasar, 3(1):1-6.

Putri,M. (2018). Pengaruh Gaya Belajar Terhadap Pemahaman Membaca Pada
Pelajaran Bahasa Inggris. Ensiklopedia of Journal, 1 (1).

Rambe,M.S.Kons.Yarni,N. (2019). Pengaruh Gaya Belajar Visual, Auditorial, Dan Kinestetikterhadap Prestasi Belajar Siswa Sma Dian Andalas Padang. Jurnal Review Pendidikan dan Pengajaran,2(2), 2655.

Riadin, Agung dan Ade Salahuddin Permadi (2019). Implementasi Pembelajaran PKn untuk Membentuk Pribadi yang Berkarakter di SD Muhammadiyah Sampit. Pedagogik: Jurnal Pendidikan, 14(1):18-28.

Rismadew,N.W.M. (2019). Perbedaan Pengaruh Pembelajaran Kontekstual Terhadap Hasil Belajar Bahasa Inggris Antara Siswa Yang Bergaya Belajar Visual, Auditori Dan Kinestetik (Di Sd It Albanna). Jurnal Pendidikan Bahasa Inggris Undiksha, 7 (1),

Rosa,E. (2018). Pengaruh Persepsi Peserta Didik Atas Gaya Belajar Dan Kecerdasan Intelektual Terhadap Prestasi Belajar Bahasa Inggris. Journal of English Language Teaching , 01 (01), 1-98

Saija,L.M. (2020). Analisis Terhadap Gaya Belajar Siswa Sekolah Menengah Di Bandung. Jurnal Padegogik 3 (1), 57 70

Sari,A.K. (2014). Analisis Karakteristik Gaya Belajar Vak(Visual, Auditorial, Kinestetik) Mahasiswa Pendidikan Informatika Angkatan 2014. Jurnal Ilmiah Edutic, 1(1),

Syamsu Rijal,S. Bachtiar,S. (2015). Hubungan antara Sikap, Kemandirian Belajar, dan Gaya Belajar dengan Hasil Belajar Kognitif Siswa. Jurnal BIOEDUKATIKA, 3(2), 15-20

Wahyuni,Y.(2017). Identifikasi Gaya Belajar (Visual, Auditorial, Kinestetik) 
Mahasiswa Pendidikan Matematika

Universitas Bung Hatta. JPPM, 10(2)

Waluyo,M.E. (2014). Revolusi Gaya Belajar

untuk Fungsi Otak. Jurnal Pendidikan

Islam, 8(2),

Wibowo,N.(2016). Upaya Peningkatan

Keaktifan Siswa Melalui

Pembelajaran Berdasarkan Gaya

Belajar Di Smk Negeri 1 Saptosari.

Jurnal Electronics, Informatics, and

Vocational Education (ELINVO),1(2)

130

Widayanti,F.D. (2013). Pentingnya

Mengetahui Gaya Belajar Siswa

Dalam Kegiatan Pembelajaran Di

Kelas. ERUDIO,2(1),

Widayanti,F.D. (2013). Pentingnya

Mengetahui Gaya Belajar Siswa

Dalam Kegiatan Pembelajaran Di

Kelas. ERUDIO,2(1) 